\title{
Spinoza en América Latina, un comentario sobre la obra de Diego Tatián ${ }^{*}$
}

Spinoza in Latin America, a comment on Diego Tatián's work

\author{
Por: Sztulwark, Diego * \\ Universidad de Buenos Aires (UBA) \\ Buenos Aires, Argentina
}

Email: dsztulwark@gmail.com

Fecha de recepción: 6/04/2019

Fecha de aprobación: 12/05/2020

DOI: $\underline{10.30972 / n v t .1614347}$

\section{Resumen}

En el presente artículo, me propongo realizar una conversación con la lectura de Spinoza realizada por Diego Tatián, indicando su relevancia para contexto político latinoamericano actual. Para ello, comienzo por señalar la existencia de una tradición que toma a Spinoza como argumento activo para coyunturas históricas específicas, en la que se insertaría la obra de Tatián. Intento poner la obra de Tatián en diálogo con otras lecturas, incluida la propia, para así mostrar su relevancia teórica y política, así como los puntos que deben ser aun discutidos. En este sentido, será importante la lectura de Johnatan Israel: discutir el spinozismo a partir de la obra de Tatián supone prolongar la constitución de una nueva ilustración radical a la realidad actual latinoamericana que, en conexión con los contextos de radicalización no europeos de nuestro tiempo, abra las puertas para trascender los límites hasta ahora impuestos por

\footnotetext{
*Este artículo retoma y actualiza los comentarios que realicé sobre la obra de Diego Tatián, en ocasión de la publicación de sus libros Spinoza. Filosofía terrena, en 2014, y Spinoza disidente, en 2019.

* Estudió Ciencia Política en la Universidad de Buenos Aires. Es docente y coordina grupos de estudio sobre filosofía y política. Se ha desempeñado como docente invitado en la Maestría de Educación de la Facultad Latinoamericana de Ciencias Sociales (FLACSO) y en la carrera de Sociología de la Facultad de Ciencias Sociales de la UBA
} 
el liberalismo, en terrenos tan cruciales como la misma definición de lo que entendemos por democracia e igualdad.

Palabras clave: Spinoza, Democracia, Latinoamérica, Ilustración, Cuerpo.

\begin{abstract}
In this article, I develop a conversation with Diego Tatián's reading of Spinoza, indicating its relevance to the current Latin American political context. For this, I begin by pointing out the existence of a tradition, in which Tatián participates, that takes Spinoza as an active argument for specific historical conjunctures. I try to put Tatián's work in dialogue with other readings, including mine, in order to show its theoretical and political relevance, as well as the points that still must be discussed. Johnatan Israel's interpretation of Spinoza is important to show that discussing Spinozism from Tatián's perspective prolongs the constitution of a radical illustration to the current Latin American reality. And, in connection with the non-European radicalization contexts of our time, it opens the possibility of transcending the limits imposed by liberalism, in areas as crucial as the very definition of democracy and equality.
\end{abstract}

Keywords: Spinoza, Democracy, Latin America, Illustration, Body.

\title{
Cómo citar este artículo:
}

APA: Sztulwark, D. (2020). Spinoza en América Latina, un comentario sobre la obra de Diego Tatián. Nuevo Itinerario, 16 (1), 104-120. Recuperado de: (agregar dirección web)

\section{Pensar a Spinoza}

Una de las estrategias más interesantes para leer a Spinoza es introducir o enfatizar conceptos que no están desplegados o, incluso, que no están presentes en la Ética. Gilles Deleuze empleó la noción de "expresión" de un modo expandido en su renovación de la comprensión de la filosofía spinoziana. Antonio Negri buscó un nuevo dinamismo materialista al introducir el concepto de "constitución", abriendo así una 
vía fecunda para pensar la relación con Marx. Étienne Balibar, por su parte, hizo el ejercicio fértil de tomar la idea de "transindividual", tal como la propone Gilbert Simondon, para mostrar hasta qué punto Spinoza se beneficia cuando es leído como un predecesor del pensador de la técnica. Más recientemente, Laurent Bove propuso la noción de "estrategia" para caracterizar, con un lenguaje proveniente del mundo de la guerra, la idea de deseo o conatus. Más que "explicar" a Spinoza, estos pensadores se dedicaron a enfatizar o inventar, por medio de intuiciones y nuevos conceptos, a un Spinoza a la altura de la experiencia contemporánea, bajo el supuesto compartido de que los conceptos no nos esperan para ser explayados o enseñados, sino que deben ser creados, discutidos, puestos en juego.

Por fuera de los centros académicos consagrados, Henri Meschonnic -en un libro recientemente traducido al castellano- propone su noción de "poema", con la cual se permite abrir una indagación largamente postergada sobre el lenguaje en Spinoza. La definición de poema, como lenguaje capaz de crear forma de vida y como forma de vida que crea lenguaje, es rastreada por él en el Tratado político. Meschonnic, poeta y traductor, descree de la enseñanza académica de la filosofía. A sus ojos, la mayoría de las veces se trata de reproducir sistemas lógicos, olvidando los marcadores afectivos que determinan el sentido del lenguaje con el que se piensa. Un rumbo compatible con el de Meschonnic en la compresión activa de la teoría de los afectos es llevado a cabo por León Rozitchner en su lectura de Spinoza. Para él, "el proceso consiste en aprender de uno mismo". Leer a Spinoza es aprender cómo pensó, y averiguar en ese aprendizaje el propio filosofar. Rozitchner había impartido clases sobre Spinoza en su exilio venezolano. En la carpeta de apuntes para sus cursos, se lee sobre la Ética: "filosofia del subdesarrollo"; y sobre el Tratado teológico-político: "contra el absoluto". La obra de Spinoza recorre por entero los trabajos de Rozitchner a la manera de los personajes del novelista Isaac Bashevis Singer: menos como un personaje a retratar y más como un interlocutor omnipresente.

En el caso de la obra de Diego Tatián, es posible encontrar momentos muy distintos. Spinoza es pensado para sostener una "impolítica", pero también, conforme avanza la coyuntura sudamericana, es el inspirador de una nueva relación entre una 
democracia que viene de abajo y unas instituciones que deben procesar estos impulsos populares en el plano del Estado, haciendo del Estado mismo un contrapoder, en un sentido opuesto a la tradición fundada en el pensamiento de Marx. Mas allá de esta evolución, que estimo abierta en el pensamiento de Diego Tatián, en sus escritos y conversaciones encuentro una constante fértil y muy desafiante: leer a Spinoza en conexión con los avatares de un territorio y una política propiamente latinoamericanos. Diría, entonces, que Tatián discute con el spinozismo al modo del siglo XX: introduciendo un término ausente o no muy desplegado (siempre se puede aludir a la mención que Spinoza hace a Brasil en una de sus cartas), a partir de esa categoría en formación que es Latinoamérica.

\section{Por una nueva ilustración radical}

En La ilustración radical, la filosofía y la construcción de la modernidad, 16501750, Jonathan Israel (2009) también relee a Spinoza a partir de un territorio y una coyuntura: la de la Europa atravesada por el fenómeno de la llustración. Este estudio erudito sobre la alta Ilustración, entendida como proceso cultural y político de secularización del mundo cristiano, se apoya en tres grandes afirmaciones, todas ellas de elevada significación política: a) la llustración no fue un fenómeno nacional (francés o inglés) sino inmediatamente paneuropeo; b) la llamada "Ilustración radical", lejos de resultar menor y/o periférica, constituyó un motor vital en la llustración en su conjunto ( $y$, en particular, en relación a la llustración moderada), demostrando incluso una mayor consistencia intelectual en el plano internacional, y c) Spinoza y el spinozismo tuvieron una centralidad clave dentro de esta última corriente (a contrapelo de las versiones mitologizadas de un Spinoza genial pero carente de influencia).

La presentación de las dos alas rivales de la llustración está en la base de todo el argumento: la llustración moderada, respaldada por numerosos gobiernos y facciones influyentes de las principales iglesias, y a partir del prestigio de figuras de la talla de Newton, Leibniz o Locke, aspiraba a vencer la ignorancia y la superstición, a 
establecer la tolerancia, a revolucionar las ideas, la educación y las actitudes por medio de la filosofía, preservando, eso sí, elementos de las viejas estructuras, consideradas esenciales, en una nueva síntesis entre la razón y la fe.

La llustración radical, en cambio, rechazaba todo compromiso con el pasado y buscaba acabar con las estructuras existentes en su totalidad; acabar no sólo con la creencia en un Dios Creador del mundo, capaz de intervenir en los asuntos humanos, sino también con la influencia política de las iglesias y las jerarquías sociales (privilegios políticos, concentración de la tierra) fundadas en cualquier principio divino.

La investigación de Israel es detallista, tanto en la descripción de la formación de las instituciones (las bibliotecas, la clandestinidad, las editoriales, la censura), las corrientes intelectuales y las tonalidades afectivas del siglo XVII, como en la presentación de las hipótesis que concentraron a un sector republicano radicalizado (un movimiento más organizado de lo que se cree) en torno al "círculo" Spinoza: la inherencia del movimiento a la materia (contra la idea de que el movimiento nace del alma o del espíritu); la extensión de la mecánica y de las leyes del movimiento y reposo a la esfera universal de la materia extensa-naturaleza (contra la división según la cual la física mecánica explicaría solo algunos movimientos, reservando el resto a las potestades divinas); la dialéctica afirmativa entre institución del poder político y multitud (contra la legitimación divina y vertical de la soberanía); el democratismo igualitario (contra la escisión entre una esfera de libertad de opinión y un acceso restringido a la tierra); la afirmación de una única sustancia eterna e infinita, Deus sive Natura (recusando tanto la idea del Dios creador, como el dualismo alma/cuerpo); la afirmación de la naturaleza como campo absoluto de inmanencia (contra la creencia en milagros); la tolerancia filosófica, republicana y antiteológica (contra la tolerancia teológica, concerniente a la libertad de culto); el combate en torno al fundamento teológico del orden social; y la negación de una autoría divina de la Biblia.

En un sentido similar, un reciente estudio de Alejandro Horowicz (2019), El huracán rojo, Francia y Rusia, 1789-1917, reconstruye al detalle la importancia del espacio territorial y político europeo como medio de despliegue de un segundo 
momento radical, fuertemente igualitarista e intelectualmente materialista, durante el período que va de la Revolución Francesa a la Revolución Rusa y al pensamiento de Marx y del marxismo. Según Horowicz, el movimiento socialista europeo fue finalmente derrotado con la Segunda Guerra Mundial. Su tesis es que el espacio de las revoluciones burguesas no fue nunca nacional, sino atlántico, y que el ciclo de revoluciones responde a problemas que conciernen al mercado mundial; de manera que el problema de las revoluciones socialistas fue que debieron resolver, en base al esfuerzo nacional, desafíos de índole continental.

Creo que es posible afirmar que la lectura de Diego Tatián sobre la obra de Spinoza se inscribe dentro del proyecto de constituir el territorio y la coyuntura política continental latinoamericana como medio para un tercer movimiento en el Occidente moderno de radicalización igualitarista. Lo que supone incluir en la práctica de la lectura, desde el comienzo, un gesto de apropiación capaz de dar continuidad a aquella Ilustración radical de cuño spinozista, sobre un nuevo plano geofilosófico, reformulando el fundamento naturalista, materialista y republicano para un contexto no-europeo. Entiendo por "no-europeo", más que un rechazo, un desplazamiento: la apertura de un espacio mental, geofilosófico productivo, desde el cual apropiarse del archivo ilustrado sin prejuicios ni subordinaciones neocoloniales.

Estimo que discutir el spinozismo a partir de la obra de Diego Tatián supone prolongar a la realidad actual latinoamericana la constitución de una nueva ilustración radical que, en conexión con los contextos de radicalización no-europeos de nuestro tiempo, abra las puertas para trascender los límites hasta ahora impuestos por el liberalismo, en terrenos tan cruciales como la misma definición de lo que entendemos por democracia e igualdad. Es decir: leer la conexión Spinoza-Marx a partir de contextos y desafíos situados y contemporáneos.

La obra de Spinoza antecede a Marx en la constitución de una ontología relacional, como base alternativa al pensamiento liberal. Desde la perspectiva de la Ilustración radical spinozista -dice Israel- los conceptos de democracia y libertad se enlazan de modo directo con el problema del acceso a la tierra y de la igualdad en el goce de la libido de mujeres y hombres. El radical ilustrado Alberto Radicati, conde de 
Passerano (1698-1737), por ejemplo, creía que la democracia y la igualdad solo se alcanzarían con la propiedad comunal de la tierra y con la abolición del matrimonio y la familia. Israel nombra una larga lista de autores radicales (Anton van Dale; Balthasar Bekker; los hermanos Koerbagh; Frederik van Leenhof; Antonio Schinella Conti; Ehrenfried Walther von Tschirnhaus; John Toland; Anthony Collins; Abraham Joannes Cuffeler; Jean-Baptiste de Boyer, marqués de Argens; Johann Georg Wachter; Henri de Boulainvilliers; Bernard Mandeville) que enseñaron la co-constitución entre intelectualidad libre, acceso igualitario a las riquezas y derecho al disfrute del propio cuerpo. La democracia y la igualdad no eran para ellos valores para la legitimación de un orden, sino criterios inmanentes a la praxis colectiva.

Durante el siglo XVIII -comenta Israel- la percepción general en Europa es que el spinozismo es la absoluta antítesis del cristianismo. El propio Israel considera evidente la semejanza entre la tensión producida por el spinozismo en el mundo intelectual de su época y la que se generó a partir de la obra de Marx y sus seguidores. En efecto, el spinozismo fue considerado en toda Europa como el más articulado y radical ataque a las autoridades bíblicas y políticas de la cristiandad. La contrafigura genial de Leibniz, con su proyecto de una filosofía compatible con la unificación de la cristiandad, lo certifica. Israel nos proporciona una imagen nítida de la influencia de Spinoza sobre una pluralidad muy grande de movimientos ilustrados, democráticos y radicales de toda Europa. Hace surgir a otro Spinoza, moldeado en la crítica del cristianismo, como modelo de toda "crítica" (para decirlo con el lenguaje del joven Marx). Un Spinoza que anticipa el uso del modelo de la crítica contra el capitalismo.

\section{Diego Tatián y la militancia política}

En 2014, Diego Tatián publica Spinoza, filosofía terrena. El taller spinozista al que recurre el autor para elaborar sus instrumentos de intervención política es laico, anti-jerárquico y democrático. No es fácil el arte de conciliar en una misma escritura verdades eternas con apuestas situadas. La filosofía terrena asume una doble coyuntura: combina la exposición de ciertos momentos del sistema spinoziano, valiosa 
contribución a la difusión y renovación del spinozismo en lengua castellana, con la vocación de abrir discusiones precisas en la política latinoamericana en los años en que el ciclo de los gobiernos progresistas retrocede. El libro consta de dos partes: una reedición algo modificada de Spinoza y el amor del mundo (2004), y una serie de capítulos nuevos referidos a cuestiones de inmediato interés político, tal como se advierte en sus títulos: "La cuestión democrática", "La izquierda maquiaveliana" y "Realismo y don del militante". En todos ellos encontramos explícitos posicionamientos en torno a la coyuntura del momento. Sin abandonar su valoración general del spinozismo -una dialéctica entre lo "salvaje" de las potencias y la "cautela" de la estrategia-, Tatián introduce, con el nombre de Maquiavelo, el problema del realismo democrático en el seno del esfuerzo de la composición democrática. Maquiavelo y Spinoza se suman con la intención de proponer la dinámica democrática como extensión y desarrollo del derecho natural, a través de la creación de instituciones que satisfagan los devenires concretos en los que se originan y efectúan las potencias de la multitud. Se trata de retomar estos problemas conceptuales de la ciencia política a la luz de los dilemas que acosan a los gobiernos llamados progresistas de la región sudamericana. América Latina es pensada, entonces, como un espacio en el que se fue abriendo una posibilidad política, a partir de la impugnación del neoliberalismo realizada desde abajo por parte de una serie de movimientos populares. El dilema que se dispone a afrontar Tatián en ese contexto es el de la fundación de una dinámica institucional que sostenga y profundice en el tiempo la dinámica democrática. Para Tatián, aparece con nuevo interés la figura del militante dentro de esa delimitación problemática; piensa en los militantes capaces de sostener estos procesos políticos.

A partir de estas claras coordenadas, el spinozismo de Diego Tatián comienza a afirmar sus proposiciones haciendo distinciones precisas. La primera de ellas, el llamado a no confundir el carácter "salvaje" de las potencias colectivas, que parten siempre de un suelo indeterminado, con un desvío de tipo anárquico que bloquee la constitución de la emancipación como política. Es la proposición del realismo político que consiste, para Tatián, en validar el nivel institucional y el específicamente estatal al 
interior del proceso democrático en curso. El estado como contrapoder, escribe. Una segunda distinción apunta a demarcar la política democrática de la secuencia revolucionaria del siglo XX, que en América Latina estuvo marcada por la figura del "hombre nuevo" propuesta por el Che Guevara -figura que Tatián considera atrapada en una dialéctica cerrada entre el "espíritu" y la "muerte", entre lo celestial y el sacrificio. Los procesos emancipatorios que él defiende se trazan a través de otras coordenadas: la amistad con los otros y con nosotros mismos, tal y como realmente somos. En efecto, la filosofía del conatus tiene como premisa absoluta la autoconservación. El rechazo de la marca revolucionaria surge de oponer el realismo maquiaveliano (no cabe considerar a los hombres como deberían ser, sino a partir de lo que son) a una comprensión santificada y moralista del revolucionario. La preocupación por sostener los procesos políticos da lugar, de este modo, a un Spinoza a la defensiva, no sólo frente a las elites neoliberales, sino también frente a las posiciones anarquistas y revolucionarias. No es sorprendente, por lo tanto, que Tatián nos recuerde que el más radical pensamiento político del siglo XVII, el de Spinoza, no surge por una inspiración teórica, sino por una motivación práctica: defender un gobierno de las embestidas ortodoxas y monárquicas, que acabarían finalmente con éste en 1672, dos años después de la publicación del Tratado Teológico Político. El realismo maquiaveliano también será empleado en tono de defensa y conservación: una perspectiva tributaria de la tradición maquiaveliana asumirá la imposibilidad de llevar adelante un proceso político orientado a producir igualdades, reparaciones e inclusiones sin contar con aparatos, punteros, dinero, alianzas no deseadas, negociaciones con frecuencia oscuras y demás.

Al repasar estas notas de lectura de la obra de Diego Tatián, no puedo evitar sentir cierto extrañamiento por el hecho de compartir las líneas centrales de su proyecto -pensar Spinoza a partir del espacio de politización sudamericano- y, al mismo tiempo, experimentar una sostenida distancia respecto al uso restringido que hace del admirable realismo político del dúo Maquiavelo-Spinoza, articulable en principio con estrategias más abiertas de problematización. Un ejemplo de esas otras 


\section{Diego Sztulwark}

posibilidades podemos encontrarlo en un texto escrito por León Rozitchner a fines de 1979, en su ya mencionado exilio venezolano:

Su filosofía (la de Spinoza) está detrás de cada uno de nosotros, y nos invita a convertirnos en el lugar donde se elabora, como experiencia de vida, lo que la mera reflexión solo enuncia como saber, y enfrentar entonces el riesgo de un nuevo e ignorado poder. Por eso nos advierte 'nadie sabe lo que puede un cuerpo'. El saber se despliega sólo luego de descubrir y ejercer ese poder. El poder colectivo se revela desde el propio cuerpo individual amplificado cuando superamos la cerrazón sensible que el terror nos impuso al separarnos de los demás" (Rozitchner, 1998: 12). ${ }^{1}$

Para Rozitchner, el conocimiento depende de la experiencia y de la conquista de una potencia colectiva que, en el caso argentino, debe enfrentar un obstáculo específico: el terror de la dictadura y del capital. Años después, ese mismo spinozismo militante guió la reflexión de Rozitchner ante un episodio extraordinario: la orden del entonces presidente Néstor Kirchner al jefe de las Fuerzas Armadas de descolgar un cuadro del dictador Jorge Rafael Videla. Para Rozitchner, lo extraordinario de aquella orden de Kirchner fue la denuncia pública de la complicidad entre política y terror como fundamento de poder. Esa denuncia fortalecía las condiciones para nuevos protagonismos colectivos, en la medida en que la potencia de aquel gesto no se viera bloqueada, castrada, detenida y pudiera, al contrario, profundizarse en otros tantos gestos capaces de prolongar su alcance, hasta alterar esa materialidad histórica aún organizada por el terror: la economía y la estructura de propiedad de la tierra. El realismo político, en el caso de Rozitchner, no trabaja sobre la base de la defensa, sino sobre el deseo de comprender y superar los obstáculos que coartan, detienen y frenan la profundización democrática. ${ }^{2}$

\footnotetext{
${ }^{1}$ León Rozitchner, Prólogo a Perón, entre la sangre y el tiempo. En el mismo texto, Rozitchner se refiere también a la obra de Maquiavelo como al saber que funda lo político en la potencia de la multitud.

${ }^{2}$ Otro ejemplo de spinozismo militante es La gratuidad del riesgo, de Miguel Benasayag, sobre la figura del Che Guevara. Para el autor, la praxis de Guevara no fue la de un voluntarista, ni debe ser leída desde el difundido mito del revolucionario sacrificial: "el Che defendía y desarrollaba un análisis basado en la multiplicidad y la complejidad, y no en bloques imaginarios a los cuales era necesario adherir".
} 


\section{Una filosofía terrena y disidente}

Unos años después, Diego Tatián publica Spinoza disidente (2019). Este último libro confirma y profundiza la vocación de articular la filosofía clásica con los conflictos del presente, en un tiempo histórico que había cambiado con la llegada de Macri y con el golpe contra el PT en Brasil, que culminaría en el gobierno de Bolsonaro. En el nuevo contexto, la reivindicación explícita de la disidencia -el derecho a sentir de otra manera- cataliza la nueva articulación entre ontología y coyuntura. La filosofía se revela política en la exacta medida en que se involucra en las controversias actuales en torno a la igualdad. El spinozismo, trabajado desde el espacio de politización latinoamericano, debe ser reelaborado ahora desde la adversidad. Spinoza disidente es un contrapunto entre coyunturas y un intento de recrear, para nuestro contexto, una "izquierda spinozista".

Esta nueva inmersión en Spinoza parte de una formulación clarificadora: por "izquierda" hay que entender la decisión programática de suscitar la potencia común de los cuerpos-de cada cuerpo y de todxs: la excomunión de Spinoza inspira la experiencia de una comunidad abierta-con vistas a resolver la llamada "cuestión social". En las páginas de Spinoza disidente hay un Ilamado a hacer de la igualdad de las inteligencias en acto la base de una nueva ofensiva por las libertades públicas. Por liberación se entiende ahora el doble movimiento que conjuga ideas libertarias con el aumento colectivo de la fuerza física en una misma tentativa de inscribir demandas igualitarias en las estructuras económicas y jurídicas. El programa spinoziano de Diego Tatián es inseparable de la elaboración de una lengua spinozista sudamericana, apta para procesar nuestras coordenadas políticas inmediatas. Pero esa lengua permanece obstaculizada por la mistificación de una fase europea del spinozismo de izquierda.

En efecto, al calor de la rebelión de 1968, autores tan influyentes como Louis Althusser, Gilles Deleuze y Alexander Matheron dieron origen a la izquierda spinozista europea. A esa izquierda, con todas sus diferencias y matices, pertenecen también autores actuales como Toni Negri y Etienne Balibar. Sin perder de vista esas diferencias y matices que encontramos entre ellos, Tatián elige medirse con 
Toni Negri, a quien tal vez considera el máximo representante de un spinozismo autonomista y militante. Es con el Spinoza de Negri con quien se propone ajustar cuentas, explicitar distancias y deslindar posiciones. Para ir rápido: si el principal estudio de Negri sobre Spinoza - La anomalía salvaje-traza las coordenadas de un antagonismo directo entre poder y potencia (entre Estado del capital y autonomía de la multitud), para Tatián la coyuntura sudamericana requiere pensarse desde otras coordenadas, en particular si se quiere dar cuenta, como es el caso, de la ya citada experiencia de los gobiernos llamados progresistas de la región.

La especificación de coyunturas históricas y la necesidad de crear una lengua específica orientan a Diego Tatián hacia la afirmación de posiciones teórico-políticas diferenciadas, en especial en relación a la compresión del papel del Estado. En línea convergente cun con otro lenguaje-con las tesis de populistas como Ernesto Laclau, Diego Tatián trata de sostener el vínculo entre radicalización democrática, Estado como institucionalidad en disputa (y no como mero instrumento del capital) y una multitud ambivalente, irreductible a su presentación intempestiva y autonomista. Más que oposiciones simples (Estado del capital versus multitud), para el autor se trata de sostener un complejo de mediaciones. La izquierda spinozista sudamericana que él propone se vuelca, de este modo, hacia la tradición nacional-popular, en la que encuentra un imaginario para establecer una continuidad entre potencia de los muchos y radicalismo instituyente. En esa apoyatura se elabora su imagen de un contrapoder que ya no asume los rasgos diáfanos del antagonismo, sino que incluso puede ser concebido como operando en el propio Estado, sin que medie revolución alguna.

En este sentido, un primer problema que se le plantea a Spinoza disidente es el carácter hiperdinámico de la propia coyuntura sudamericana sobre la que se elabora en acto: la experiencia de los gobiernos progresistas no puede ser fechada $-\mathrm{y}$ no hay coyuntura sin fechas- sin ser incluida en una secuencia más amplia que abarque tanto 
a las luchas sociales previas como a la deriva reaccionaria posterior. ${ }^{3}$ Es necesario tener presente, por tanto, estas variaciones de la coyuntura para captar la correlación entre situación política y lecturas de Spinoza. Con las secuencias desplegadas, pueden percibirse al menos tres momentos de esta correlación:

Durante la experiencia de la crisis de cambio de milenio, y en el contexto de la emergencia de nuevas organizaciones populares, se leyó a Spinoza de un modo militante, autonomista y en clave de ruptura con el Estado neoliberal de los años noventa. Un Spinoza influido por los textos de Negri, pero sobre todo de Deleuze (son los años en los que Cactus edita las clases En medio de Spinoza), que se proponía ligar destitución política, creación de formas de vida y autorganización popular.

En época de los gobiernos progresistas, pensadores de la talla de Marilena Chauí (y Diego Tatián) se propusieron enfatizar, en los momentos de inscripción de derechos populares en el Estado (básicamente en torno a la experiencia del PT y del kirchnerismo), en las universidades públicas (San Pablo, Córdoba) y en los encuentros entre amigxs, una intensa práctica de formación e intervención (decenas de publicaciones), que dieron lugar a una nueva generación de investigadores spinozianos -teóricos y políticos- más influenciados por Althusser y Balibar que por Deleuze y Negri.

El 2015 argentino y el desastre brasileño plantean nuevas preguntas, balances y desafíos. La fuerza de los hechos lleva a pensar un Spinoza antifascista, como parte de una filosofía de la adversidad. Una serenidad materialista antes que una ansiedad voluntarista. Dos libros se tornan, al menos para mí, importantes: La estrategia del conatus, de Laurent Bove, y Spinoza, poema del pensamiento, del poeta Henri Meschonnic. El primero presenta una pragmática del deseo, una desmoralización de las prácticas democráticas y de los modos de hacer de lo colectivo en su relación con el mercado y la guerra. El segundo libro vuelve a sacarlo de la academia para reencontrar la fuerza del lenguaje libertario y combativo del spinozismo.

\footnotetext{
${ }^{3}$ A lo que se suma el desafío de caracterizar la situación sudamericana actual, tras la aparición de un movimiento insurreccional en Chile, un golpe de estado en Bolivia, la victoria de un gobierno de derecha en Uruguay y la experiencia del gobierno de Fernández en la Argentina.
} 
Con Spinoza disidente, Diego Tatián ambiciona una tarea intelectual y política apasionante. Procura un espacio filosófico clásico para poner a discutir estos tres momentos sudamericanos (ipero quizás ya estemos en un cuarto, o quinto!) de las militancias filosóficas spinozianas. Este marco clásico se forma mediante la aproximación de la filosofía de Spinoza al ya citado realismo republicano de Nicolás Maquiavelo, pero también al comunismo de Marx. Spinoza como una suerte de nexo virtuoso o cúspide comunicativa entre estos dos grandes pensamientos. Tanto el florentino como el barbado de Tréveris resultan clave en el diseño de dispositivos subversivos a partir de la crítica materialista. En ambos, la crítica de las mistificaciones del poder (la teología en el siglo XVI; la economía política en el XIX) da lugar a una praxis histórica abierta y constituyente de subjetividad.

Para alguien que pasó una parte de su vida leyendo a Spinoza, a la izquierda spinozista de la Europa de 1968, y prestando atención a las coyunturas sudamericanas presentes, resulta casi imposible no desear escribir su propio Spinoza disidente. Cada quien lo haría de acuerdo con sus propias obsesiones. Del Spinoza que investiga el secreto de la servidumbre y concibe lo político como democracia, ligando la crítica a la potencia y a la institución, seguramente subrayaría el carácter insurgente de su ética (como hacía León Rozitchner), es decir, la particular comprensión de la institución tal y como emerge a la luz de la insurrección (poder de lo común). Planteo, entonces, tres obsesiones a favor de la disidencia spinoziana sudamericana actual:

El carácter autónomo (nunca idéntico al Estado) del contrapoder no deriva de un dogmatismo anti-institucional per se (no es dogmáticamente anti-estatal), sino de un cuestionamiento del modo de acumulación de capital que opera por detrás -o junto- a las formas estatales que hemos conocido. En ese sentido, "autonomía" no es una doctrina opuesta a otras (populismo), sino una perspectiva de cuestionamiento a un dispositivo de mando (político, social y económico) que destruye o precariza las mediaciones sociales. Quizás la principal tarea de la izquierda spinozista latinoamericana, en la coyuntura actual, sea superar el bloqueo de la praxis política que surge de una comprensión absurda de la autonomía, según la cual ésta implicaría una espontaneidad sin mediaciones (no 
hay contrapoder ni democracia sin organización, sin dispositivos colectivos, sin instituciones del común; ipero se trata de mediaciones horizontales, no verticales!), y de una teoría estatista de las mediaciones que, en la práctica, precariza el potencial de las organizaciones militantes, dispositivos colectivos e instituciones comunes. La urgencia de un replanteo de la democracia, de la calidad de su problematización-resolución, depende de los impulsos igualitarios capaces de derrotar los impulsos neofascistas del presente.

El 2015 argentino es un punto de inflexión que impone realizar balances de la coyuntura previa. El historiador Javier Trímboli llama "consumismo" al rasgo predominante del período. No solo por la ampliación efectiva del consumo popular anterior a esa fecha, sino por el carácter inmediatamente subjetivador de esa relación específica con el consumo. El desafío de pensar la relación entre democracia y consumo al interior de un período en el cual la subjetivación de mercado es tan poderosa -incluso y sobre todo durante los gobiernos progresistas- supone imaginar modalidades de politización de la economía política. Politizar el consumo supone revisar la distancia supuesta entre una realidad material de mercado (potencia neoliberal) y la realidad simbólica de la política (potencia política).Si lo político no se sumerge en la economía, si no descubre allí dispositivos de contrapoder capaces de crear potencias democráticas e igualitarias -bajo la forma de coordinación de luchas-, inmanentes a la propia realidad material de la economía, lo político como discursividad y autonomía relativa de lo simbólico pierde su materialidad efectiva. Cuando la retórica de la igualdad se desencarna, se condena a la impotencia.

El realismo democrático de la igualdad necesita un dispositivo en el que pueda concretarse. En ausencia de revoluciones, el contrapoder surge como capacidad de vetar o limitar iniciativas desigualitarias. En Geometría de las pasiones, Remo Bodei demuestra la magnitud de la distancia política entre el sensualismo spinoziano y el violento ascetismo jacobino que impregnó la imagen de la revolución. El esfuerzo por perseverar en el ser, el deseo o conatus como premisa de la virtud y camino hacia la utilidad común, está en conflicto con la figura del "hombre nuevo" leída en 
clave moralista y sacrificial. La concreción de dispositivos igualitaristas nuevos requiere balances críticos específicos, tanto del pasado revolucionario como de la actual crisis de la democracia al menos en tres aspectos:

La forma humana sobre la que escribe Ernesto Guevara partía de la crítica de la vigencia de la ley del valor (la relación entre mercancías como medida de la relación entre personas). La revolución no resolvió el problema, pero sí lo planteó con claridad. El realismo democrático radical no puede subestimar esta cuestión del poder subjetivante del valor. De otro modo, se pierde la diferencia específica entre democracia radical y democracia como concepto en crisis, incapaz de producir nuevas igualdades.

Concretar la igualdad supone medios de inscribir ideas igualitarias en las estructuras económicas y jurídicas, lo cual implica una capacidad de las clases condenadas a la desigualdad para reunir la fuerza física para sostener, proponer y defender estas ideas. Sin esa combinación de impulsos, ideas y fuerzas no solo no es posible experimentar nuevas igualdades (como lo vemos en la actual democracia en crisis), sino que no habrá forma de defender las actuales.

La democracia como aquel proceso en el que se explora la posibilidad política de una igualdad efectiva no se reduce al respeto por el Estado de derecho. La actual crisis de la democracia consiste en que el Estado de derecho -el gobierno de acuerdo con las leyes- se ha convertido en un eficaz instrumento de desactivación de procesos democráticos. En este contexto, el llamado "fracaso" de la revolución tiene un efecto preciso: desvincular la íntima relación entre democracia -incluso burguesa- y el proceso de lucha revolucionaria que le dio origen y le permitió desarrollarse. Es decir, desacreditar todo dispositivo capaz de volver a vincular deseos, ideas y fuerzas en torno al problema de la igualdad.

Spinoza disidente de Diego Tatián es, como sus otros libros sobre Spinoza, una importante fuente de aprendizaje sobre los nexos entre filosofía y política. Afirma un pensamiento situado, y un sereno no-colonialismo. No un anticolonialismo reactivo, sino la afirmación de un derecho a manotear el archivo europeo para utilizarlo sin reverencias. Para hacer, sencillamente, lo que se nos dé la gana. 
Spinoza en América Latina, un comentario sobre la obra de Diego Tatián

\section{Bibliografía}

Horowicz, A. (2019). El huracán rojo. De Francia a Rusia 1789-1917. Buenos Aires: Crítica.

Israel, J. (2009). La ilustración radical: La filosofía y la construcción de la modernidad. 1650-1750. México: Fondo de Cultura Económica.

Meschonnic, H. (2016). Spinoza, poema de pensamiento. Buenos Aires: Tinta Limon Ediciones y Cactus.

Rozitchner, L. (1998). Perón: entre la sangre y el tiempo. Lo inconsciente y la política. Buenos Aires: Catálogos.

Tatián, D. (2004). Spinoza y el amor del mundo. Buenos Aires: Altamira.

Tatián, D. (2014). Spinoza, filosofía terrena. Buenos Aires: Ediciones Colihue.

Tatián, D. (2019). Spinoza disidente. Buenos Aires: Tinta Limón. 